Beobachtung auf der Sternwarte in Düsseldorf.

Bei wechselnder, meist sehr ungünstiger Luftbeschaffenheit notierte ich:

M. Z. Gr.

$14^{\mathrm{h}} 40^{\mathrm{m}} \cdot 7$

Der Umriß des ganzen Ostrandes des Mondes erscheint im Sucher wesentlich dunkler als der des Westrandes.

14 II.4 Erste Trübung im Refraktor.

I 4 2.8 Finsternis hat begonnen.

I $44843^{\text {s }}$ Der graue Schațten reicht bis zum Grimaldi und zu einem nördlicheren Krater, anscheinend Kepler.

I 4 I I 3 Grimaldi ganz im Schatten.

I 5 O. I Schatten reicht bis zum Copernicus. Wolken.

I 525 I verschwand Arago im Schatten.

I 53545 Tycho, erste Berührung mit der Schattengrenze.

I $5375^{8}$ Tycho, zweite " " "

I6 17 Mit Ausnahme einer schmalen Kalotte im Süden ist der ganze Mond verfinstert.

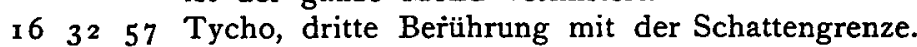

I6 3449 Tycho, vierte 》 " "

Düsseldorf, I914 März I8. Wilhelm Luther.

Beobachtung auf der Sternwarte in Königsberg, Pr.

Als Beobachtungsinstrumente dienten mir der Plösslsche Dialyt ( $0_{5} \mathrm{~mm}$ Obj.-Öffnung, Vergr. 78), sowie der Kometensucher von Reinfelder und Hertel (r $20 \mathrm{~mm}$ Obj.Öffnung, Vergr. 20). Um $14^{\mathrm{h}} 39^{\mathrm{m}} \mathrm{m}$. Zt. Greenwich ist der Schatten deutlich ein Stück vorgerückt. Es wurden nun folgende Momente im Plössl beobachtet:

M. Z. Gr.

I $4^{\mathrm{h}} 49^{\mathrm{m}} \cdot 3$ Aristarch, äußere Berührung.

52.2 Grimaldi, äußere Berührung.

55.9 Euler, äußere Berïhrung.

I 50.6 Pytheas, äußere Berührung.

2. I Plato, Bisektion.

3.6 Copernicus, Bisektion.

5.0 Archimedes, innere Berührung.

II.4 Kaukasus im Terminator.

I 7.8 Bulliald, Bisektion.

25.5 Walter, Bisektion.

32.8 Macrobius, Bisektion.

34.8 Picard A, Bisektion.
M. Z. Gr.

$15^{\mathrm{h}} 3^{6^{\mathrm{m}}} \mathrm{I}$ Picard, Bisektion.

38.3 Tycho, äußere Berührung.

40.3 Tycho, Bisektion.

42.0 Tycho, innere Berührung.

42.5 Firmicus und Appollonius, Bisektion unsicher.

I $5^{\mathrm{h}} \mathrm{o}^{\mathrm{m}}$ ist der rötliche Erdschein im Kometensucher sehr deutlich und auffallend, weniger im Plössl. ${ }^{1} 5^{\mathrm{h}} 36^{\mathrm{m}}$ ist er im Kometensucher intensiv rötlich. Die beschatteten Meere sind deutlich zu erkennen. - Der Himmel war klar und die Luft ruhig. Núr um $15^{\mathrm{h}} 20^{\mathrm{m}}$ zogen leichte Cirren über den Mond. Die Fortsetzung der Beobachtung wurde durch eintretende Dämmerung, sowie durch zu tiefen Stand des Mondes und dazwischen tretende Bäume unterbrochen.

$$
\text { Königsberg, I9 I4 März 25. E. E. Kühne. }
$$

Beobachtung zu Sonneberg.

Die Beobachtung war vom Wetter wenig begünstigt, weshalb nur eine geringe Zahl von Schattenantritten erhalten werden konnte. Als Instrument diente mein Refraktor von $52 \mathrm{~mm}$ Öffnung, Vergr. 55.

M. E. Z.

I $5^{\mathrm{h}} 53^{\mathrm{m}} \cdot$ O Ostrand des Sinus Iridum noch frei, doch im tiefen Halbschatten (in Wolkenlücke).

I 6 7.3 Schattengrenze zwischen Archimedes und Aristyll. I 4.8 Ostrand des Mare Serenitatis soeben eingetreten.

28.8 Schattengrenze etwa $I^{\prime}$ östlich von Katharina und Theophilus.

5 1.8 Schattengrenze am Westrande des Mare Nectaris (unsicher, durch Wolken).

Sichere Beobachtungen konnten nur bei ganz klarem Mond erfolgen, wobei der Erdschatten ziemlich scharf begrenzt erschien. Beim Dazwischentreten leichter Wolken wurde der Schatten sofort verschwommen und schien sich stark auszudehnen. Der verfinsterte Teil des Mondes war anfangs düster grau und nahm später, besonders an den Rändern, rötliche Färbung an. Soweit festgestellt werden konnte, war einige Zeit vor der größten Phase die ganze Mondscheibe ziemlich hell. Gegen $17^{\mathrm{h}}$ traten dicke Nebelwolken auf, welche weitere Wahrnehmungen verhinderten.

Sonneberg, S.-M., I9I4 April 26. Cuno Hoffmeister.

\title{
Double star measures
}

made with the 23-inch refractor of the Princeton Univ. Observatory. By Raymond S. Dugan.

Under each star is given

I. The date.

2. The position angle.

3. The number of measures of position angle.

4. The distance.

5. The number of measures of double distance.

6. The power used.

7. Line joining the eyes at right angles to $(R)$, parallel to $(P)$, the line joining the stars.

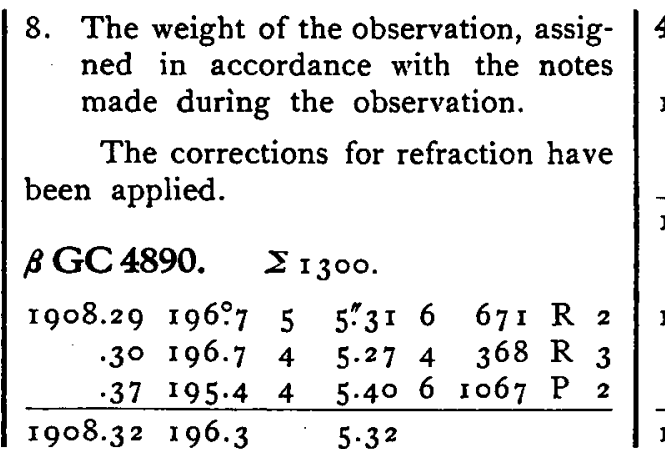

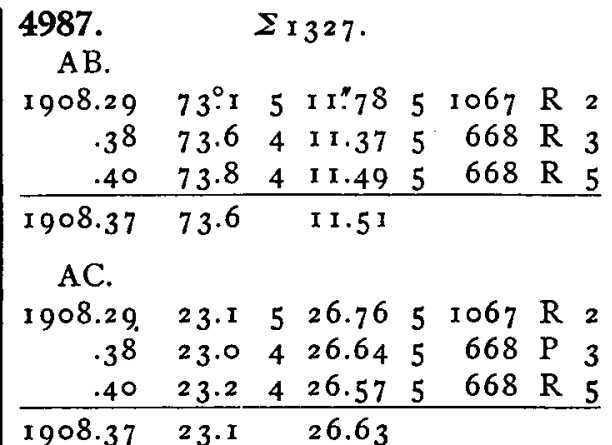

